\title{
Editores, autores e avaliadores: vamos jogar frescobol?
}

Prof. Dr. Hélio ARthur Reis Irigaray ${ }^{1}$

\author{
${ }^{1}$ Fundação Getulio Vargas / Escola Brasileira de Administração Pública e de EMPreSAs, Rio de Janeiro - RJ, BRASIL
}

O editorial desta edição especial é dedicado a leitores, autores e avaliadores. Vocês são o Cadernos EBAPE.BR. Agradecemos por esta parceria e esperamos que possamos continuar trabalhando juntos.

Gostaria de compartilhar com vocês algumas reflexões sobre as etapas de submissão, avaliação e publicação (ou não) de um artigo. Ao todo, é um processo complexo, muitas vezes demorado, angustiante e, no final, pode ser frustrante ou prazeroso para todas as partes envolvidas.

Como editor-chefe implementei o sistema de desk review contínuo, visando a dar uma primeira resposta aos autores o mais rápido possível. Ademais, procuro estar mais próximo dos autores, enviando, da minha conta pessoal de correio eletrônico, o primeiro parecer. Da mesma forma, sempre me coloco à disposição para sanar qualquer dúvida que possa persistir; pois é função dos editores zelar pela lisura e transparência do fluxo processual.

Em um segundo momento, o trabalho é encaminhado para dois avaliadores, em trabalho voluntário, que, ao final, recomendam a aprovação, ajustes ou rejeição do texto. Quando não há consenso, acionamos um terceiro avaliador, o que pode demandar mais tempo.

Infelizmente, nem sempre, a relação entre autores e avaliadores é harmoniosa. Às vezes é marcada por comentários pouco elegantes e desconfiança. Diante disso, é importante que nunca nos esqueçamos de que somos membros da mesma comunidade, cujo objetivo maior é contribuir para o avanço das discussões acadêmicas, que podem beneficiar nossas organizações e sociedade.

Para tal, editores, avaliadores e autores não podem se engajar numa disputa onde há vencedores e perdedores. Fica aqui o convite para que, em uma relação saudável, joguemos frescobol.

O frescobol, esporte criado nas praias do Rio de Janeiro, é jogado por dois jogadores de forma colaborativa. No frescobol cultivam-se a amizade e o comprometimento nas jogadas; dessa forma, não há nem vencedores, nem perdedores. Esta metáfora é um convite à esperança de um ambiente acadêmico mais saudável.

A esperança, definida por Kierkegaard (1989) como a "paixão do possível", atualiza as nossas possibilidades de sonhar e de projetar o futuro (RICOEUR, 1969) entre as ilusões da modernidade e as desilusões da pós-modernidade.

Somos como os jovens descritos por Arendt (1994) e que atualmente vivem na tremenda insegurança de poder não ter um futuro. Ainda assim, nunca podemos abrir mão de nossos ideais.

Ideais que se fizeram presentes em todos os artigos desta edição.

No primeiro artigo, Gazi Islam, o nosso mais novo membro do Conselho Editorial, e Neha Chatwani, em coautoria, discutem, em "Identificações humanitárias: respostas heterogêneas à complexidade institucional do Médecins Sans Frontières" como uma única lógica é mantida mediante atos e práticas heterogêneas com base em uma forte identificação com a lógica do humanitarismo. 
Em o "Uso discricionário das receitas de petróleo no Brasil: dinâmicas federativas", Beni Trojbicz e Catarina lanni Segatto analisam o caso brasileiro de centralização federal das receitas do petróleo e mostram como as preferências das jurisdições podem direcionar a dinâmica federal por meio de mecanismos federativos do centro.

Thiago Magalhães, Carolina Andion e Graziela Dias Alperstedt propõem um enfoque analítico e um caminho metodológico para compreender os processos de aprendizagem coletiva, coconstrução e difusão de conhecimento nos ecossistemas de inovação social colocados em prática por meio de laboratórios vivos de inovação social, no artigo "Laboratórios vivos de inovação social e ação pública: um enfoque analítico e um caminho metodológico baseados no pragmatismo".

Em "Transparência e accountability de algoritmos governamentais: o caso do sistema eletrônico de votação brasileiro", Douglas Morgan Fullin Saldanha e Marcela Barbosa da Silva identificam as características de transparência e accountability do sistema eletrônico de votação brasileiro por meio de estudo de caso.

Daniela Martins Diniz, Fabricio Molica de Mendonça, Fátima Bayma de Oliveira e Anderson de Souza Sant'Anna, em "Mecanismos de transferência de conhecimento interorganizacional: um estudo na maior instituição brasileira de pesquisa agropecuária", analisam, da perspectiva teórica da transferência de conhecimento interorganizacional, o papel desses mecanismos no desempenho da transferência de conhecimento entre uma instituição brasileira de pesquisa pública e suas empresas licenciadas.

"Gamificação nas organizações: processos de aprendizado e construção de sentido" é o título do trabalho de Soraia Finamor Neidenbach, Vanessa Martines Cepellos e Jussara Jéssica Pereira. Os autores discutem como são percebidos os processos de aprendizado e a construção de sentido da gamificação como ferramenta organizacional, baseando-se nos relatos de seis expertises na área e na análise temática.

Maria Tereza Tomé de Godoy e Helenides Mendonça analisam o papel da liderança transformacional na competência adaptativa e, ao mesmo tempo, testam o papel mediador da autodeterminação da relação apresentada por meio da satisfação das necessidades psicológicas de autonomia, de pertencimento, de competência e de realização, em "Competência adaptativa: um estudo sobre a influência da autodeterminação e da liderança transformacional".

"Mobilidades no labirinto: tensionando as fronteiras nas carreiras de mulheres", escrito por Aline Mendonça Fraga e Sidinei Rocha-de-Oliveira, é um ensaio teórico no qual os autores argumentam que a mobilidade, sobretudo geográfica e social, pode ter reduzida disponibilidade para mulheres, em razão de fronteiras que engendram pontos de imobilidade, ancorados por relações socioculturais, políticas, organizacionais e biológicas.

Fernando Ressetti Pinheiro Marques Vianna, Francis Kanashiro Meneghetti, Juliana Previatto Baltini Tonon e Leonardo Tonon, por meio de um estudo etnográfico, "Inclusão excludente e exclusão includente: estudos sobre a ralé em um clube social", analisam de que modo a ralé é socialmente excluída de determinadas situações e incluída em outras e por qual motivo.

Em “Marketing de experiência: um estudo dos aspectos conceituais", Maria Teresa Grimaldi Larocca, Rodrigo Ladeira, Áurio Lúcio Leocádio da Silva e Ricardo Coutinho Mello revisam a evolução e os atuais conceitos de marketing de experiência segundo os principais autores que se dedicaram ao entendimento desse campo.

Laís Rodrigues e Marcus Wilcox Hemais analisam, da perspectiva decolonial, processos históricos imperialistas que possibilitaram a incorporação de um modelo eurocêntrico de autorregulamentação na criação do Sistema Brasileiro de Autorregulamentação Publicitária, o SBAP, no artigo intitulado "Influências eurocêntricas no Sistema Brasileiro de Autorregulamentação Publicitária: pesquisa histórica sob uma perspectiva decolonial".

Sob a mesma Weltanschauung, "Agridoce: cozinhas profissionais pós-coloniais na pós-modernidade", escrito por Carlos Henrique Gonçalves Freitas, Cíntia Rodrigues e Valdir Machado Valadão Junior, expõe instâncias de desigualdades replicadas nas cozinhas de restaurantes finos na cidade de Uberlândia.

"No limite da razão: o deliberar e a phrónesis no trabalho prisional" é o estudo de Déris Oliveira Caitano e Maurício Serva, cujo objetivo foi verificar na experiência dos agentes penitenciários, em um complexo prisional de segurança máxima, elementos que caracterizem um quadro de evidências da phrónesis. 
Fabio José Ferraz e Denio Munia Benfatti apresentam as operações urbanas consorciadas (OUCs) como alianças públicoprivadas geradoras de valor público desenvolvidas em meio a um contexto de globalização e financeirização do mercado imobiliário, de restrições fiscais e de primazia dos interesses privados na produção do espaço urbano, em "Certificados de potencial adicional de construção como mecanismo de financiamento das operações urbanas consorciadas ou como instrumento especulativo?".

“Competição enquanto representação ideológica no ambiente ferroviário estadunidense: uma historiografia entre 1859 e 1869" é a pesquisa de Alexandre Hochmann Béhar e Marcos Gilson G. Feitosa, cujo objetivo foi analisar as aproximações ideológicas a dimensões relativas à competição no ambiente ferroviário estadunidense entre os anos de 1859 e 1869.

Tenham uma boa leitura!

Prof. Dr. Hélio Arthur Reis Irigaray

Editor-chefe 


\section{REFERÊNCIAS}

ARENDT, H. Some Questions of Moral Philosophy. Social Research, v. 61, n. 4, p. 739-764, 1994. Disponível em: <http://www.jstor.org/ stable/40971058>. Acesso em: 05 nov. 2020.

KIERKEGAARD, S. The Concept of Anxiety: a simple psychologically orienting deliberation on the dogmatic issue of hereditary sin. Princeton: Princeton University Press, 1989.
RICOEUR, P. Guilt, Ethics and Religion. Royal Institute of Philosophy Lectures, n. 2, p. 100-117, 1968. Disponível em: <http://doi. org/10.1017/S0080443600010918>. Acesso em: 05 nov. 2020. 
